\title{
THE IMPLANT INFECTION PARADOX: WHY DO SOME SUCCEED WHEN OTHERS FAIL? OPINION AND DISCUSSION PAPER
}

\author{
C. Yue ${ }^{1 \dagger}$, B. Zhao ${ }^{2 \dagger}$, Y. Ren ${ }^{2}$, R. Kuijer ${ }^{1}$, H.C. van der Mei ${ }^{1}$, H.J. Busscher ${ }^{1}$ and E.T.J. Rochford ${ }^{1 *}$ \\ ${ }^{1}$ University of Groningen, University Medical Centre Groningen, Department of Biomedical Engineering, \\ Antonius Deusinglaan 1, 9713 AV Groningen, The Netherlands \\ ${ }^{2}$ University of Groningen, University Medical Centre Groningen, Department of Orthodontics, Hanzeplein 1, \\ P.O. Box 30001, 9700 RB, Groningen, The Netherlands
}

†Contributed equally to paper

\begin{abstract}
Biomaterial-implants are frequently used to restore function and form of human anatomy. However, the presence of implanted biomaterials dramatically elevates infection risk. Paradoxically, dental-implants placed in a bacteria-laden milieu experience moderate failure-rates, due to infection (0.0-1.1\%), similar to the ones of jointarthroplasties placed in a near-sterile environment $(0.1$ $1.3 \%$ ). Transcutaneous bone-fixation pins breach the immune-barrier of the epidermis, exposing underlying sterile-tissue to an unsterile external environment. In contrast to dental-implants, also placed in a highly unsterile environment, these pins give rise to relatively high infection-associated failure-rates of up to $23.0 \%$. Herein, we attempt to identify causes as to why dentalimplants so often succeed, where others fail. The major part of all implants considered are metal-made, with similar surface-finishes. Material choice was therefore discarded as underlying the paradox. Antimicrobial activity of saliva has also been suggested as a cause for the success of dental-implants, but was discarded because saliva is the implant-site-fluid from which viable bacteria adhere. Crevicular fluid was discarded as it is largely analogous to serum. Instead, we attribute the relative success of dental-implants to (1) ability of oral tissues to heal rapidly in the continuous presence of commensal bacteria and opportunistic pathogens, and (2) tolerance of the oral immune-system. Inability of local tissue to adhere, spread and grow in presence of bacteria and an intolerant immune-system are identified as the likely main causes explaining the susceptibility of other implants to infection-associated failure. In conclusion, it is the authors' belief that new anti-infection strategies for a wide range of biomaterial-implants may be derived from the relative success of dental-implants.
\end{abstract}

Keywords: Implant infection, immune responses, host, pathogens, infection risk, biofilms.

*Address for correspondence:

E.T.J. Rochford

University of Groningen

University Medical Centre Groningen

Department of Biomedical Engineering

Antonius Deusinglaan 1

9713 AV Groningen, The Netherlands.

Telephone number: +31503633127

E-mail: e.rochford@umcg.nl

\section{Introduction}

Increased life expectancy has led to the use of a diverse range of biomaterials, with the purpose of restoring or maintaining the function and form of the human anatomy (Busscher et al., 2012). Biomaterial-associated infections are the main cause of medical implant failure (Le et al., 2014), often requiring the total removal of the implant, aggressive debridement and a prolonged course of antibiotics. Infection-associated failure rates of implants vary depending on a number of factors, including: associated co-morbidities, presence of trauma, overall condition of patients, sterility of the wound and surgery, post-surgical care, material used and the surgical site.

Of particular interest is the comparison between dental and orthopaedic implant failure rates due to infection and the sterility of these surgical sites. Joint arthroplasties are placed in largely "sterile" tissue, yet experience moderate infection-associated failure rates (see Fig. 1 and 2), which are, incidentally, similarly as low as in implantfixation of damaged jawbone (Shaik et al., 2014). The Nordic Arthroplasty Register, including 432,168 total hip arthroplasties reported a failure rate due to infection of $0.6 \%$, with the highest risk occurring in the first three months after surgery (Dale et al., 2012). In a review of 347,889 total hip arthroplasties with a follow up period of 10 years, general implant failure rates of $4.1-10.0 \%$ were reported within 10 years, dependent upon implant type (Makela et al., 2014), of which 0.1-1.1\% were identified as infection-associated failure within the first six months after surgery. Note that in the case of joint arthroplasties, the term "sterile" tissue should be used cautiously as tissue surrounding orthopaedic implant sites is almost certainly contaminated by low levels of bacteria during surgery or later, possibly from haematogenous sources. However, this still represents a low level of bacterial contamination compared to dental implant sites. Dental implants are placed in the oral cavity containing a vast number of commensal bacteria and opportunistic pathogens (see Fig. 1 and 2), yet only experience moderate infection-associated failure rates (see Fig. 1) of up to $1.1 \%$. The infectionassociated failure rate for dental implants, given in Fig. 1 , coincides with recent data on dental implant failure in general. In a group of 11,311 implants, general failure was reported for $1.4 \%$ of all implants within 1 year and $2.0 \%$ after 9 years (Derks et al., 2014). In another study, $1.7 \%$ of 198,538 dental implants failed within a median time of 247 days (Antalainen et al., 2013). These general failure rates occur for different reasons, amongst which is infection. 


\begin{tabular}{|l|l|l|}
\hline Implant & $\begin{array}{l}\text { Infection-Associated } \\
\text { Failure Rate (\%) }\end{array}$ & References \\
\hline Joint Arthroplasty & $0.1-1.3$ & $\begin{array}{l}\text { Dale H et al ., 2012; Makela KT et al ., 2014; } \\
\text { Lindgren JV et al ., 2014; Pedersen AB et al ., 2010; } \\
\text { Schrama JC et al ., 2010; lorio R et al ., 2012 }\end{array}$ \\
\hline Dental Implant & $0.0-1.1$ & $\begin{array}{l}\text { Buser D et al ., 1997; Östman P et al ., 2012; } \\
\text { jetursson BE et al ., 2007; Stach RM and Kohles SS, } \\
2003\end{array}$ \\
\hline $\begin{array}{l}\text { External Fixator/ } \\
\text { Transcutaneous Pin }\end{array}$ & $2.0-23.0$ & $\begin{array}{l}\text { Patterson MM, 2005; Kraemer P et al ., 2010; } \\
\text { Schalamon J et al ., 2007 }\end{array}$ \\
\hline
\end{tabular}

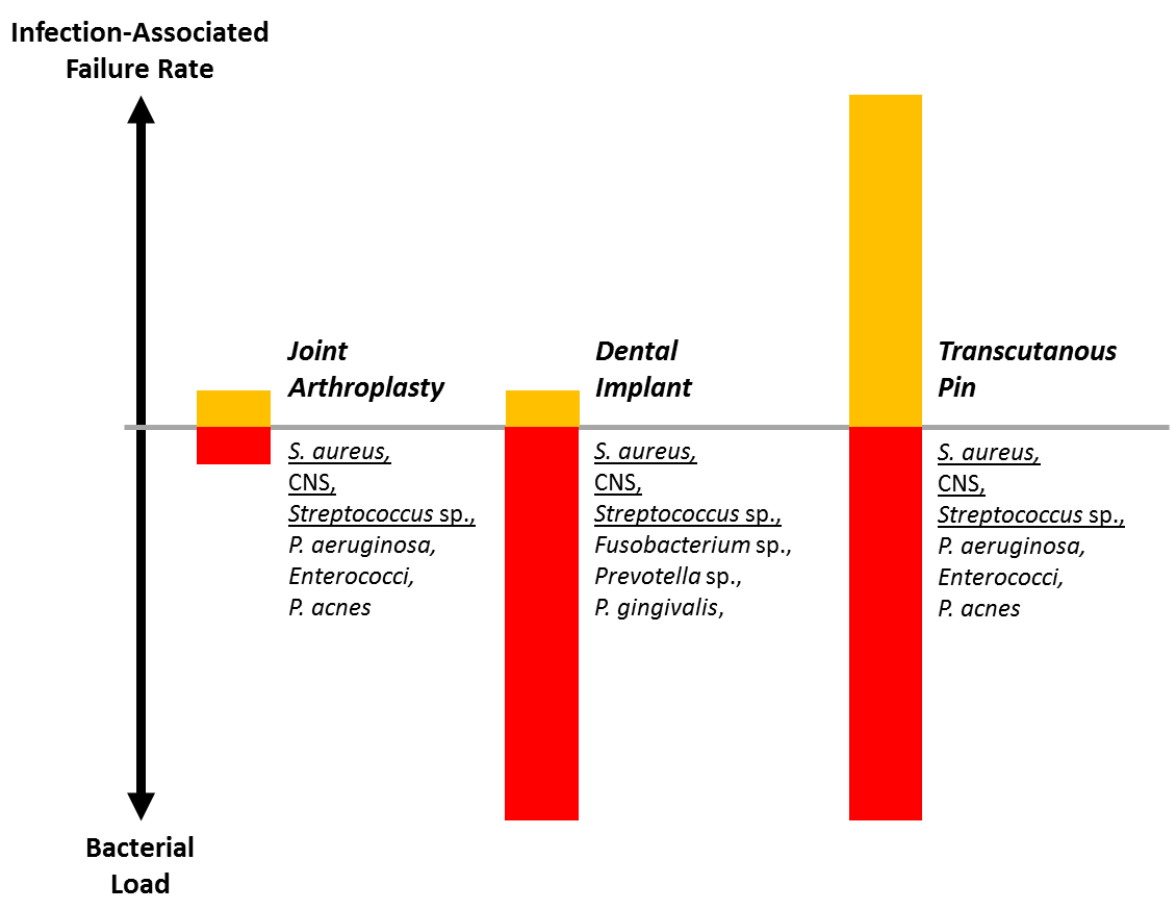

Fig. 1. Illustration of the implant infection paradox: bacterial load is not predictive of infection-associated failure rates. The graph reflects the high bacterial loads encountered by dental implants and transcutaneous pins, while their infection-associated failure rates vary dramatically as opposed to joint arthroplasties characterised by a low bacterial load and low infection-associated failure rate. In addition, the most common pathogens of each site are listed; those underlined have been reported for all implant types. (CNS refers to coagulase negative staphylococci). Exact infection rates for each site are shown in the table, together with references.

Note: not all infection-associated failure rates given in the literature for the three implant scenarios distinguish between early and late failure, as we discuss in the introduction section of this article. Moreover, reasons for and timescales of "early" and "late" differ for the different implant scenarios. Early infection in joint arthroplasties is often associated with bacterial contamination during surgical implantation. However, microorganisms can remain dormant on an implant surface for several years before they cause infection resulting in failure (Aboltins et al., 2014). Equally so, the second most common route of infection through haematological spreading from infection elsewhere in the body, can cause clinical signs of infection any time after implantation.

That they are in the range of reported infection-associated failure rates (compare Fig. 1), suggests that infection is also the major cause of failure for dental implants. Both the data summarised in Fig. 1, as well as the above analysis, indicate that despite vastly different bacterial loads in the orthopaedic and dental implant scenarios, failure rates due to infection are remarkably similar.

This represents a paradox that can be further extended to include transcutaneous pins used in external fixators to treat complicated fractures, control damage in trauma and lengthen limbs. Transcutaneous pins can be considered to be the orthopaedic analogue of dental implants: both implant types are typically made of metals and breach the innate immune barrier of the epidermis, exposing the underlying "sterile" tissue to the external environment and creating an epithelial-free edge (see Fig. 2). Due to this breach, much like in one-step placement of dental implants above the alveolar crest (Villar et al., 2012), the 

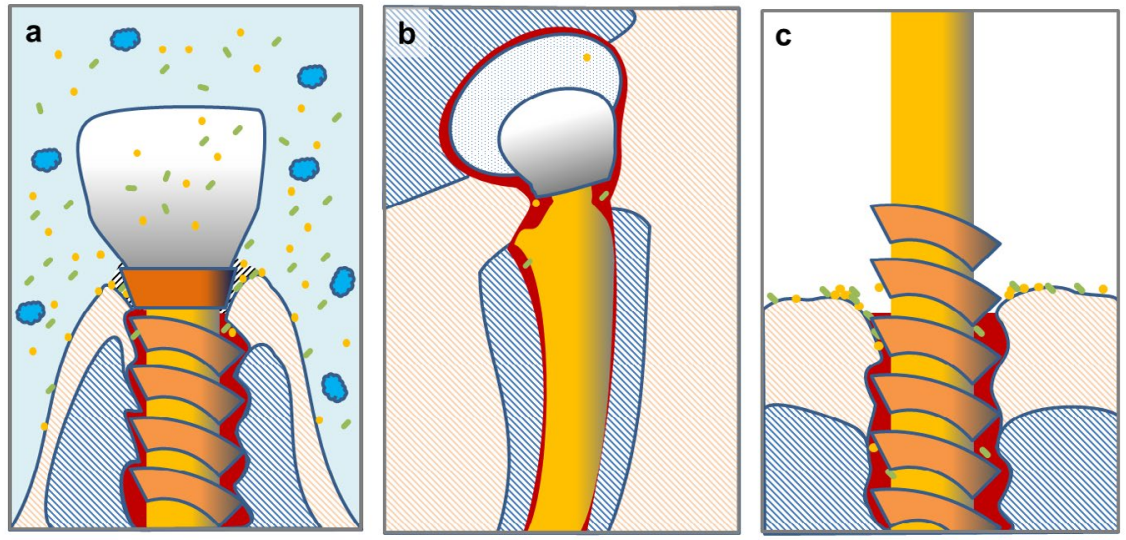

Fig. 2. Schematics of key similarities and differences in the three different implant scenarios:

(a) dental implants

(b) hip arthroplasties and

(c) external fixators.

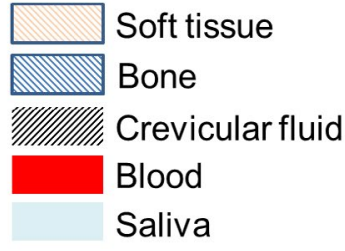

Titanium screw

Implant neck

Polymer cup bacterial load to which transcutaneous pins are exposed is relatively high, constituting both the skin microbiome and contamination from the non-sterile external environment. Also, in the two step placement of dental implants - when the implants are placed at the level of the alveolar crest and covered by gingival tissue during undisturbed healing uncovering of the implant for abutment placement requires subsequent formation of a soft tissue seal against the pressure of the high oral bacterial load, as well as soft tissue adaption to the neck of the implant and final restoration. Despite the similarities between dental implants and transcutaneous pins, with respect to epithelial down growth in the wound (Chehroudi and Brunette, 2002) and bacterial load, the infection-associated failure rate for external fixators reported over the life of the device ranges from 2-23\% dependent on the implant application and length of use (see Fig. 1).

Together, these observations reveal the full paradox and lead to the following question: Why do implants placed in the oral cavity resist infection so effectively, yielding relatively low infection-associated failure rates whilst other implants sites do not? By solving the causes of this paradox, new pathways for the prevention and treatment of biomaterial-associated infections in general may become available, potentially requiring a shift in research paradigm. Therefore, in the current article, we will evaluate the factors that influence infection and associated failure in the above three implant scenarios in order to explain why dental implants succeed when others fail.

\section{Implant materials}

All implant types involved in the implant infection paradox include a major metal component, commonly titanium, which is applied in all the discussed implant sites and therefore can be used as a comparison. Within each implant type, slight variations in the surface characteristics, mainly in hydrophobicity and roughness, of the materials are available. Joint arthroplasties and dental implants are available with hydroxyapatite coatings (Hailer et al., 2015; Lee et al., 2000), mainly to stimulate osseointegration. However, with respect to infection-associated failure, a study of 116,069 total hip arthroplasties revealed no clinically significant effect of hydroxyapatite coatings in comparison to standard micro-rough titanium (Hailer et $a l ., 2015)$. In dental materials, failure due to infection was approximately twice as prevalent with machined implant surfaces $(1.1 \%)$ in comparison to osseotite acid-etched implants (Stach and Kohles, 2003). Overall, however, the clinical effects of material choice with respect to infection-associated failure rates are small if demonstrable at all. More effective implant materials may exist in the preclinical literature, but these have yet to make their way to regular clinical use. The lack of evidence for materialinduced differences in failure rates due to infection, combined with the similarity of the materials applied in both orthopaedic and dental applications, suggest that other biological factors must be responsible for the paradox.

\section{Implant site fluids}

Upon implantation, a biomaterial is immediately in contact with complex host bodily fluids. The exact nature of these fluids is patient and implant site dependent (Wilson et al., 2005). Blood serum is present in most tissues of the body and contains a diverse array of proteins; including complement and immunoglobulins, key mediators of early immune responses. Dental implants, external fixators and internal orthopaedic implants will all come into contact with serum components; however, in contrast to the other sites, additional factors in the form of saliva and crevicular fluid are encountered in the oral cavity. The presence of antimicrobial peptides within saliva and the constant turnover of the microbial population, by removing 
microorganisms through shear, are involved in the maintenance of a healthy oral microbiome. An extensive review of antimicrobial factors present in saliva, such as defensins and cystatins, can be found in an article by Gorr and Abdolhosseini (2011). Furthermore, crevicular fluid located where the gingiva directly contacts the tooth or implant surface, contains tissue exudate, plasma proteins, antimicrobial peptides, immune cells and other immunological components such as immunoglobulins and cytokines (Pisano et al., 2005; Shillitoe and Lehner, 1972; Skapski and Lehner, 1976). Qualitatively, the content of crevicular fluid is very similar to that of serum. Quantitative levels of $\operatorname{IgG}, \operatorname{IgA}$, IgM and complement C3 are two- to four-fold higher in serum than in crevicular fluid (Shillitoe and Lehner, 1972). Therefore, neither the qualitative similarity nor the quantitative differences between crevicular fluid and serum found around orthopaedic implants can be major factors in our paradox.

Together, the role that both saliva and crevicular fluid play in the development of implant associated infection is less clear. Saliva itself contains approximately $10^{9}$ viable bacteria per $\mathrm{mL}$ (Petti et al., 2001), which leads to the colonisation of dental implants by around $10^{5}$ potentially pathogenic bacteria $\mathrm{cm}^{-2}$ after just $30 \mathrm{~min}$ exposure (AlAhmad et al., 2013). Thus, by acting as a source of potential pathogens, the presence of saliva cannot be directly related to reducing infection risk in the oral cavity. The ability of bacteria, including potential pathogens, to colonise dental surfaces rapidly, in the form of oral biofilm, on a daily basis would suggest that the antimicrobial capabilities in the oral cavity are limited. Ultimately, this means that the host fluids in the oral cavity cannot be the cause of the relatively low infection-associated failure rates of dental implants.

\section{Implant site bacterial strains}

Early bacterial contamination of implants and implant sites is generally considered unavoidable and accordingly in all implant scenarios discussed, combinations with antibiotic prophylaxis and post-operative hygiene measures are applied, details depending upon the patient, surgeon and nature of the implant. The specific composition of the bacterial load encountered by implants varies dependent upon the implant site (Benito et al., 2014; De Bruyn et al., 2013; Mombelli and Decaillet, 2011; Stoodley et al., 2011), although it must be emphasised that the complexity of the oral microbiome is almost beyond description, encompassing several hundreds of strains (Dewhirst et al., 2010). Orthopaedic implant infections are most commonly caused by a small number of pathogenic strains, including Staphylococcus aureus, coagulase negative staphylococci and streptococci (Peel et al., 2012), all of which are also implicated in peri-implantitis (Mombelli and Decaillet, 2011) (Fig. 1) and present in large numbers in saliva. For example staphylococci are present in saliva of $84 \%$ of the population at concentrations of $10^{2}-10^{4}$ colony forming units per $\mathrm{mL}$ and constitute a common cause of dental implant infection (Ohara-Nemoto et al., 2008), though the infection-associated failure rates remain remarkably low.
A key difference is that an arthroplasty will be surrounded by largely "sterile" tissue, containing low quantities of bacteria if any, whereas a dental implant is placed in a milieu containing high numbers of both commensal strains and opportunistic pathogens (Wade, 2013). Much of the microbiota present in the oral cavity form a symbiotic relationship with the host, maintaining a so-called healthy microbiome which can extend to the surface of an implant through competitive exclusion and bacteriocin release. Streptococcus gordonii and Lactobacillus strains for example, produce hydrogen peroxide that inhibits the growth of other bacteria (Jakubovics et al., 2008). Many other commensals produce bacteriocins or bacteriocin-like substances, which actively kill many other microorganisms (Kreth et al., 2009; Santagati et al., 2012).

Although the presence of a large number of commensal strains is unique to the oral cavity, and may locally suppress growth of opportunistic pathogens, in many patients the oral microbiome often shifts in an unhealthy direction leading to caries and periodontal diseases (Berezow and Darveau, 2011). Therefore, the authors' belief that the presence of high numbers of commensal strains and opportunistic pathogens exerting competitive exclusion cannot be implicated in an explanation of the implant infection paradox.

\section{Healing}

The soft tissue seal at the external face of a transcutaneous implant represents an important barrier to prevent infection, the rapid restoration of which provides protection from pathogens. Clinically, it has been observed that oral mucosal wounds demonstrate faster healing with minimal scar formation as compared with epidermal wounds (Häkkinen et al., 2000; McKeown et al., 2007; Schrementi et al., 2008), despite similar spatial and temporal processes being involved (McKeown et al., 2007; Schrementi et al., 2008; Sciubba et al., 1978). For example, 3 days after injury, collagen fibrils in wounded oral mucosa already appear to be similar to those of unwounded mucosa, whilst fibrils in skin wounds are still smaller and less uniform than unwounded skin even at 14 days post-injury (Schrementi et al., 2008). Furthermore, saliva promotes healing by maintaining a moist environment conducive to host cell viability and contains an abundance of growth factors including epidermal growth factors, transforming growth factor (TGF)- $\alpha$ and $\beta$, fibroblast growth factors, nerve growth factors and insulin like growth factors (Zelles et al., 1995).

The fast healing of oral tissue in the continuous presence of commensal bacteria and opportunistic pathogens may have developed as an evolutionary outcome in response to the eruption of teeth. In a dental implant scenario, this enables a non-osteogenic soft tissue seal around the neck of an implant to form rapidly and protect the osseointegrated part against invasion of periodontopathogens towards the bone (Chai et al., 2012). Periodontal ligament fibroblasts have even been demonstrated to take advantage of the presence of Streptococcus mutans, increasing $\beta 1$ integrins expression (Engels-Deutsch et al., 2011). This 
specific bacterial stimulation, without the development of infection, may therefore improve healing that in turn reduces future infection risk and associated failure. This type of stimulation has not been observed in other tissues, such as around orthopaedic implants, and may account in part for the low infection-associated failure rates of dental implants in comparison to transcutaneous fixators.

\section{Local immunological factors}

When contamination of an implant occurs, it is the task of the host immune system to prevent infection. Many foreign bodies, including commensal microorganisms and food particles are encountered in the oral cavity and oral mucosal tolerance is important in preventing excessive and destructive immune responses. In normally sterile tissues, there is no requirement for tolerance towards foreign bodies, as any foreign material normally needs to be removed to prevent infection. Therefore, oral immunology is not analogous to host responses in the usually "sterile" tissues present around orthopaedic implants. This discrepancy between tolerances can be observed using a number of characteristics unique to the oral mucosa.

Within the oral mucosa, dendritic cells - specifically Langerhans cells - have been identified as important arbiters of developing immune responses (Mowat, 2005; Stumbles et al., 2003; Williamson et al., 2002). However, in contrast to the skin, dendritic cells present in the gingiva demonstrate a particular orientation, with the dendrites facing towards the external environment explicitly for sampling antigen from the oral cavity (Ito et al., 1998). This feature is advantageous, when reacting to the large external challenges. Furthermore, the mucosal membrane demonstrates a degree of permeability to sample material present in the oral cavity, resulting in the regular stimulation of these cells. This feature is not shared with the skin, which is largely impermeable to the external environment and, below the stratum corneum, normally antigen free.

A further difference between the epidermis and oral mucosa is the abundance and location of T-lymphocytes (Van Loon et al., 1989). In normal skin, T-lymphocytes are localised around the blood vessels in the papillary layer. In contrast, the oral mucosa contains an increased number of cells at the epithelium-papillary boundary, closer to the external surface. This distribution is likely because most invasive foreign material associated with skin tissue will be present in the vasculature or in blood associated with wounds. In the oral cavity the largest challenge arises from the immediate external environment; therefore, the greater number and more homogenous distribution of T-lymphocytes in oral mucosa may aid the tissue in responding to the external threat (Van Loon et al., 1989). Furthermore, salivary polymorphonuclear neutrophils demonstrate decreased phagocytic activity and ingestion rates, yet increased ability to kill bacteria following ingestion, in comparison to the skin equivalents (Lukac et al., 2003). This may reflect a more balanced immune response, in general associated with the oral cavity, due to life-long adaptation to the presence of bacteria and foreign materials, trading broad inflammation for a more specific reaction to antigen.

In the presence of an implant, diminished inflammation may be a key feature of the rapid repair of oral mucosa (Szpaderska et al., 2003). Lower levels of neutrophil, macrophage, and T-cell infiltrations are consistently observed in oral wounds compared with corresponding skin wounds, drawing parallels with rapidly healing foetal wounds (Häkkinen et al., 2000; Wilgus, 2008). Furthermore, RT-PCR analysis has shown that oral wounds stimulate lower quantities of inflammatory cytokine interleukin (IL)-6 and CXCL-1 (the murine analogue of IL-8) gene expression, and less pro-fibrotic cytokine TGF- $\beta 1$ than skin wounds in mice (Mak et al., 2009; Schrementi et al., 2008; Szpaderska et al., 2003). This implies that the inflammatory response to an oral wound is reduced, thus permitting a greater degree of sensitivity to react with individual signals to the specific nature of the pathogenic challenge rather than generating a non-specific broad inflammatory response. In addition, life-long immunomodulation induced by commensal bacteria may also induce a broader effect, whereby microorganisms can influence immune responses at the implant site. For example, in the gastrointestinal tract, probiotic bacteria have been shown to stimulate interferon (IFN)- $\gamma$ production, modulate phagocytosis and decrease lymphocyte proliferation (Isolauri et al., 2001). The exact role of bacterial immunomodulation in the oral cavity has yet to be fully investigated; however, similar hostcommensal-pathogen relationships may be expected as in the gut. Despite the comparatively limited research into oral host-bacteria interactions, an example of commensal bacteria influencing gingival responses and inducing tolerogenic effects has been observed. The presence of the cytoplasmic glycolytic enzyme enolase, as associated with the bacterial cell wall of Streptococcus sobrinus was found to induce immunosuppressive responses, resulting in a notable increase in serum levels of IL-10 in mice following injection of the protein (Veiga-Malta et al., 2004). Therefore, it may be inferred that the presence of immunosuppressive commensals in the oral cavity prevents the immune system from being overrun by the inflammatory virulence factors of pathogens. In general, the immune responses within "sterile" tissues is intolerant to any foreign body incursion, as demonstrated by the non-specific broad inflammatory responses observed in subcutaneous tissues (Prabhakara et al., 2011), which may lead to an ineffectual response to both the implant and a pathogenic challenge. In many ways, members of the commensal oral microbiota may be viewed as an extension of the host immune system by forming bilateral interactions. In normally "sterile" tissues, the lack of both bacterially induced immunological tolerance and competitive exclusion combined with the more aggressive immune responses may result in relatively small bacterial challenges being able to induce infection more effectively and evade immune responses. 
The crux of the paradox

In this article, we attribute the decreased infectionassociated failure rate of dental implants as compared to orthopaedic ones to two factors: (1) the ability of soft tissue to adhere, spread and grow in the presence of bacteria in the oral cavity, due to the evolutionary prerequisite for this tissue to deal with an erupting dentition; and (2) the generation of a specific local immunological deficit due to the presence of a foreign body in non-oral tissues (Elek and Conen, 1957). This deficit prevents a targeted and controlled host response to pathogens from developing, as it does in individuals without a biomaterial implant, eventually resulting in a biomaterial-associated infection and possible failure. We believe that these two factors constitute the crux of the paradoxically different infection susceptibilities, and associated failure rates, in the different implant scenarios discussed. Oral tissue is different from other tissues surrounding implants, as it has evolved to better accept bacterial presence; while the oral immune system is unique, due to an innate tolerance towards many bacterial strains and the presence of food particles, which may extend to implant materials.

\section{A potential shift in paradigm}

By trying to understand the causes of the relative success of dental implants, we can potentially design new antiinfection strategies for a wider range of implants. The unique scenario of dental implants in the oral cavity may serve as an example to make "sterile" tissues accustomed to bacterial presence and induce more tolerant immune responses to implant materials, along with more targeted immune responses against pathogens. This line of thinking may require a significant paradigm shift in translational implant research. Orally inspired treatment options could include, for example, the application of specific cytokine profiles observed when dental implants are placed. The aim of these treatments should be to reduce the general inflammation associated with the presence of a foreign body in normally sterile tissues, permitting targeted antibacterial responses to develop. Alternatively, giving "sterile" tissues experience with bacterial pathogens through exposure to, or vaccination with, the most prominent pathogens threatening a particular type of implant prior to surgery may also be an option to reduce infection-associated implant failure. This "experience" may then allow the immune responses to target contaminating bacteria more effectively, over the general inflammation caused by the presence of the implanted foreign body. By modulating the host response in such a way and stimulating an oral tissue type of response, we might use the paradox in our favour and reduce the risk of infection-associated failure within a wide range of biomaterial implants.

\section{Acknowledgements}

CY would like to thank the China Scholarship Council and W. J. Kolff institute for financial support.

\section{Disclosure statement}

The authors declare the following competing financial interest(s): Henk J. Busscher is also director of a consulting company, SASA BV (GN Schutterlaan 4, 9797 PC, Thesinge, The Netherlands). The authors declare no potential conflicts of interest with respect to authorship and/or publication of this article. Opinions and assertions contained herein are those of the authors and not construed as necessarily representing views of the funding organisation or their respective employers.

\section{References}

Aboltins C, Daffy J, Choong P, Stanley P (2014) Current concepts in the management of prosthetic joint infection. Intern Med J 44: 834-840.

Al-Ahmad A, Wiedmann-Al-Ahmad M, Fackler A, Follo M, Hellwig E, Bächle M, Hannig C, Han JS, Wolkewitz M, Kohal R (2013) In vivo study of the initial bacterial adhesion on different implant materials. Arch Oral Biol 58: 1139-1147.

Antalainen AK, Helminen M, Forss H, Sandor GK, Wolff J (2013) Assessment of removed dental implants in Finland from 1994 to 2012. Int J Oral Maxillofac Implants 28: $1612-1618$.

Benito N, Franco M, Coll P, Gálvez ML, Jordán M, López-Contreras, J, Pomar V, Monllau JC, Mirelis B, Gurguí M (2014) Etiology of surgical site infections after primary total joint arthroplasties. J Orthop Res 32: 633-637.

Berezow AB, Darveau RP (2011) Microbial shift and periodontitis. Periodontol 2000 55: 36-47.

Buser D, Mericske-Stern R, Bernard P, Pierre J, Behneke A, Behneke N, Hirt HP, Belser UC, Lang NP (1997) Long-term evaluation of non-submerged ITI implants. Part 1: 8-year life table analysis of a prospective multi-center study with 2359 implants. Clin Oral Implants Res 8: 161-172.

Busscher HJ, Van der Mei HC, Subbiahdoss G, Jutte PC, Van den Dungen JJ, Zaat SA, Schultz MJ, Grainger DW (2012) Biomaterial-associated infection: locating the finish line in the race for the surface. Sci Transl Med 4: 153 rv110.

Chai WL, Brook IM, Palmquist A, Van Noort R, Moharamzadeh K (2012) The biological seal of the implantsoft tissue interface evaluated in a tissue-engineered oral mucosal model. J R Soc Interface 9: 3528-3538.

Chehroudi B, Brunette DM (2002) Subcutaneous microfabricated surfaces inhibit epithelial recession and promote long-term survival of percutaneous implants. Biomaterials 23: 229-237.

Dale H, Fenstad AM, Hallan G, Havelin LI, Furnes O, Overgaard S, Pedersen AB, Kärrholm J, Garellick G, Pulkkinen P (2012) Increasing risk of prosthetic joint infection after total hip arthroplasty: 2,778 revisions due to infection after 432,168 primary THAs in the Nordic Arthroplasty Register Association (NARA). Acta Orthop 83: 449-458. 
Derks J, Hakansson J, Wennstrom JL, Tomasi C, Larsson M, Berglundh T (2014) Effectiveness of implant therapy analyzed in a Swedish population: early and late implant loss. J Dent Res DOI: 10.1177/0022034514563077.

De Bruyn H, Bouvry P, Collaert B, De Clercq C, Persson GR, Cosyn J (2013) Long-term clinical, microbiological, and radiographic outcomes of Brånemark ${ }^{\mathrm{TM}}$ implants installed in augmented maxillary bone for fixed full-arch rehabilitation. Clin Implant Dent Relat Res 15: 73-82.

Dewhirst FE, Chen T, Izard J, Paster BJ, Tanner ACR, Yu WH, Lakshmanan A, Wade WG (2010) The human oral microbiome. J Bacteriol 192: 5002-5017.

Elek SD, Conen PE (1957) The virulence of Staphylococcus pyogenes for man; a study of the problems of wound infection. Br J Exp Pathol 38: 573-586.

Engels-Deutsch M, Rizk S, Haïkel Y (2011) Streptococcus mutans antigen I/II binds to $\alpha 5 \beta 1$ integrins via its A-domain and increases $\beta 1$ integrins expression on periodontal ligament fibroblast cells. Arch Oral Biol 56: 22-28.

Gorr SU, Abdolhosseini M (2011) Antimicrobial peptides and periodontal disease. J Clin Periodontol 38(Suppl 11): 126-141.

Hailer NP, Lazarinis S, Mäkelä KT, Eskelinen A, Fenstad AM, Hallan G, Havelin L, Overgaard S, Pedersen AB, Mehnert F, Kärrholm J (2015) Hydroxyapatite coating does not improve uncemented stem survival after total hip arthroplasty! Acta Orthopaed 86: 1-8.

Häkkinen L, Uitto VJ, Larjava H (2000) Cell biology of gingival wound healing. Periodontol 2000 24: 127-152.

Iorio R, Williams KM, Marcantonio AJ, Specht LM, Tilzey JF, Healy WL (2012) Diabetes mellitus, hemoglobin $\mathrm{A} 1 \mathrm{C}$, and the incidence of total joint arthroplasty infection. J Arthroplasty 27: 726-729.

Isolauri E, Sutas Y, Kankaanpaa P, Arvilommi H, Salminen S (2001) Probiotics: effects on immunity. Am J Clin Nutr 73: 444S-450S.

Ito H, Takekoshi T, Miyauchi M, Ogawa I, Takata T, Nikai H, Takemoto K (1998) Three-dimensional appearance of Langerhans cells in human gingival epithelium as revealed by confocal laser scanning microscopy. Arch Oral Biol 43: 741-744.

Jakubovics NS, Gill SR, Vickerman MM, Kolenbrander PE (2008) Role of hydrogen peroxide in competition and cooperation between Streptococcus gordonii and Actinomyces naeslundii. FEMS Microbiol Ecol 66: 637644.

Kraemer P, Lee MB, Englehardt H, Chapman JR, Bransford RJ (2010). Infectious pin complication rates in halo vest fixators using ceramic versus metallic pins. J Spinal Disord Tech 23: e59-e62.

Kreth J, Merritt J, Qi F (2009) Bacterial and host interactions of oral streptococci. DNA Cell Biol 28: $397-$ 403.

Le DH, Goodman SB, Maloney WJ, Huddleston JI (2014) Current modes of failure in TKA: infection, instability, and stiffness predominate. Clin Orthop Relat Res 472: 2197-2200.

Lee JJ, Rouhfar L, Beirne OR (2000). Survival of hydroxyapatite-coated implants: a meta-analytic review. J Oral Maxillofac Surg 58: 1372-1379.
Lindgren JV, Gordon M, Wretenberg P, Kärrholm J, Garellick G (2014). Validation of reoperations due to infection in the Swedish Hip Arthroplasty Register. BMC Musculoskelet Disord, 15: 384.

Lukac J, Mravak-Stipetić M, Knezević M, Vrcek J, Sistig S, Ledinsky M, Kusić Z (2003) Phagocytic functions of salivary neutrophils in oral mucous membrane diseases. J Oral Pathol Med 32: 271-274.

Mak K, Manji A, Gallant-Behm C, Wiebe C, Hart DA, Larjava H, Häkkinen L (2009) Scarless healing of oral mucosa is characterized by faster resolution of inflammation and control of myofibroblast action compared to skin wounds in the red Duroc pig model. J Dermatol Sci 56: 168-180.

Makela KT, Matilainen M, Pulkkinen P, Mfenstad A, Havelin L, Engesaeter L, Furnes O, Pedersen AB, Overgaard S, Kärrholm J, Malchau H, Garellick G, Ranstam J, Eskelinen A (2014) Failure rate of cemented and uncemented total hip replacements: register study of combined Nordic database of four nations. BMJ 348: f7592.

McKeown ST, Barnes JJ, Hyland PL, Lundy FT, Fray MJ, Irwin CR (2007) Matrix metalloproteinase-3 differences in oral and skin fibroblasts. J Dent Res 86: 457-462.

Mombelli A, Decaillet F (2011) The characteristics of biofilms in peri-implant disease. J Clin Periodontol 38(Suppl 11): 203-213.

Mowat AM (2005) Dendritic cells and immune responses to orally administered antigens. Vaccine 23: 1797-1799.

Ohara-Nemoto Y, Haraga H, Kimura S, Nemoto TK (2008) Occurrence of staphylococci in the oral cavities of healthy adults and nasal oral trafficking of the bacteria. $\mathrm{J}$ Med Microbiol 57: 95-99.

Östman P, Hellman M, Sennerby L (2012) Ten years later. Results from a prospective single-centre clinical study on 121 oxidized (TiUnite ${ }^{\mathrm{TM}}$ ) Brånemark implants in 46 patients. Clin Implant Dent Res 14: 852-860.

Patterson MM (2005). Multicenter pin care study. Orthop Nurs 24: 349-360.

Pedersen AB, Svendsson JE, Johnsen SP, Riis A, Overgaard S (2010). Risk factors for revision due to infection after primary total hip arthroplasty: a populationbased study of 80,756 primary procedures in the Danish Hip Arthroplasty Registry. Acta Orthop 81: 542-547.

Peel TN, Cheng AC, Buising KL, Choong PF (2012) Microbiological aetiology, epidemiology, and clinical profile of prosthetic joint infections: are current antibiotic prophylaxis guidelines effective? Antimicrob Agents Chemother 56: 2386-2391.

Petti S, Tarsitani G, D'Arca AS (2001) A randomized clinical trial of the effect of yoghurt on the human salivary microflora. Arch Oral Biol 46: 705-712.

Pisano E, Cabras T, Montaldo C, Piras V, Inzitari R, Olmi C, Castagnola M, Messana I (2005) Peptides of human gingival crevicular fluid determined by HPLC-ESIMS. Eur J Oral Sci 113: 462-468.

Pjetursson BE, Sailer I, Zwahlen M, Hämmerle $\mathrm{CH}$ (2007). A systematic review of the survival and complication rates of all-ceramic and metal-ceramic 
reconstructions after an observation period of at least 3 years. Part I: single crowns. Clin Oral Implants Res 18(s3): 73-85.

Prabhakara R, Harro JM, Leid JG, Keegan AD, Prior ML, Shirtliff ME (2011) Suppression of the inflammatory immune response prevents the development of chronic biofilm infection due to methicillin-resistant Staphylococcus aureus. Infect Immun 79: 5010-5018.

Santagati M, Scillato M, Patane F, Aiello C, Stefani S (2012) Bacteriocin-producing oral streptococci and inhibition of respiratory pathogens. FEMS Immunol Med Microbiol 65: 23-31.

Schalamon J, Petnehazy T, Ainoedhofer H, Zwick EB, Singer G, Hoellwarth ME (2007) Pin tract infection with external fixation of pediatric fractures. J Pediatr Surg 42: 1584-1587.

Schrama JC, Espehaug B, Hallan G, Engesæter LB, Furnes O, Havelin LI, Fevang BTS, (2010) Risk of revision for infection in primary total hip and knee arthroplasty in patients with rheumatoid arthritis compared with osteoarthritis: A prospective, population-based study on 108,786 hip and knee joint arthroplasties from the Norwegian Arthroplasty Register. Arthritis Care Res 62: 473-479.

Schrementi ME, Ferreira AM, Zender C, DiPietro LA (2008) Site-specific production of TGF-beta in oral mucosal and cutaneous wounds. Wound Repair Regen 16: 80-86.

Sciubba JJ, Waterhouse JP, Meyer J (1978) A fine structural comparison of the healing of incisional wounds of mucosa and skin. J Oral Pathol 7: 214-227.

Shaik M, Raju TS, Rao NK, Reddy CK (2014) Effectiveness of $2.0 \mathrm{~mm}$ standard and $2.0 \mathrm{~mm}$ locking miniplates in management of mandibular fractures: a clinical comparative study. J Maxillofac Oral Surg 13: 47-52.

Shillitoe EJ, Lehner T (1972) Immunoglobulins and complement in crevicular fluid, serum and saliva in man. Arch Oral Biol 17: 241-247.

Skapski H, Lehner T (1976) A crevicular washing method for investigating immune components of crevicular fluid in man. J Periodontal Res 11: 19-24.

Stach RM, Kohles SS (2003) A meta-analysis examining the clinical survivability of machined-surfaced and osseotite implants in poor-quality bone. Implant Dent 12: 87-96.

Stoodley P, Conti SF, DeMeo PJ, Nistico L, MeltonKreft R, Johnson S, Darabi A, Ehrlich GD, Costerton JW, Kathju S (2011) Characterization of a mixed MRSA/MRSE biofilm in an explanted total ankle arthroplasty. FEMS Immunol Med Microbiol 62: 66-74.

Stumbles PA, Upham JW, Holt PG (2003) Airway dendritic cells: co-ordinators of immunological homeostasis and immunity in the respiratory tract. APMIS 111: 741-755.

Szpaderska AM, Zuckerman JD, DiPietro LA (2003) Differential injury responses in oral mucosal and cutaneous wounds. J Dent Res 82: 621-626.

Van Loon LA, Krieg SR, Davidson CL, Bos JD (1989) Quantification and distribution of lymphocyte subsets and Langerhans cells in normal human oral mucosa and skin. J Oral Pathol Med 18: 197-201.
Veiga-Malta I, Duarte M, Dinis M, Tavares D, Videira A, Ferreira P (2004) Enolase from Streptococcus sobrinus is an immunosuppressive protein. Cell Microbiol 6: 79-88.

Villar CC, Huynh-Ba G, Mills MP, Cochran DL (2012) Wound healing around dental implants. In: Oral Wound Healing: Cell Biology and Clinical Management, Larjava H. (Ed.), Wiley-Blackwell, pp287-312.

Wade WG (2013) The oral microbiome in health and disease. Pharmacol Res 69: 137-143.

Wilgus TA (2008) Immune cells in the healing skin wound: Influential players at each stage of repair. Pharmacol Res 58: 112-116.

Williamson E, Bilsborough JM, Viney JL (2002) Regulation of mucosal dendritic cell function by receptor activator of NF- $\kappa \mathrm{B}$ (RANK)/RANK ligand interactions: impact on tolerance induction. J Immunol 169: 3606-3612.

Wilson CJ, Clegg RE, Leavesley DI, Pearcy MJ. (2005) Mediation of biomaterial-cell interactions by adsorbed proteins: a review. Tissue Eng 11: 1-18.

Zelles T, Purushotham K, Macauley S, Oxford G, Humphreys-Beher M (1995) Concise review: saliva and growth factors: the fountain of youth resides in us all. $\mathrm{J}$ Dent Res 74: 1826-1832.

\section{Discussion with reviewers}

L. Harris: The authors make no reference to the fact that we brush our teeth regularly to remove bacteria build up on our teeth. Is this not an important difference in the environment of the dental implant that would influence the success of such implants? Can the authors comment on this?

Authors: Post-operative hygiene measures are implemented, in association with all of the surgeries discussed in the manuscript. For dental implants, common care instructions involve the use of antibacterial mouthwashes in the days following surgery and routine brushing thereafter. These measures will reduce bacterial colonisation in the short term. However, the rapid recolonisation of bacteria following cleaning is evidenced by the daily build-up of oral biofilms even in healthy individuals. Therefore, the microbial load is rapidly restored. Furthermore, brushing alone does not remove bacteria from the oral soft tissues and critical sites such as the crevices and the gingival margins surrounding implants.

L. Harris: Does the implant biomaterial have any influence on the success of dental implants compared to other implants? Are some dental implant types more susceptible to infections than others?

Authors: The specific bulk and surface characteristics of a material impact upon biological interactions, including infection risk. However, dental implants, transcutaneous pins and arthroplasties are manufactured from similar materials, as illustrated in Figure 2. Titanium and its alloys are the most prevalent dental implant materials and these devices generally feature a polished neck to reduce bacterial adhesion at the gingival margin, which has been shown to decrease infection rates. In addition, novel 
biomaterials and coatings have also been suggested, in the literature, but rigorous clinical evaluations of their infection rates are not yet available for statistical reasons (Busscher et al., 2012, text reference). To illustrate this point for the dental implants, in a multi-centre study including 281 patients and six different implant types, representing the largest clinical and microbiological analysis of patients with peri-implantitis, authors themselves cautioned for over-interpretation of their results due to statistical reasons and called for the need of prospective, multi-centre studies (Charalampakis et al., 2012).

D. Grainger: Oral re-epithelialisation rates are not addressed in this opinion paper but could play a role in more rapid wound healing, synchronised with the attenuated inflammatory response the authors describe. Is anything known about the signalling between oral epithelial cells and leucocytes, which produces this rapid healing that is different from soft tissue (i.e., dermal) healing?

Authors: Rapid re-epithelialisation rates in the oral cavity, included as part of the healing paragraph, show that oral healing proceeds relatively fast in comparison to skin. This may offer some explanation as to the difference between dental and transcutaneous implants. However, the immediate sealing of the surgical site for arthroplasties negates this factor in explaining the paradox. In general, oral wounds stimulate a much reduced infiltration of inflammatory cells in comparison with skin wounds. Furthermore, oral wounds have been observed to contain far lower amounts of inflammatory cytokines such as IL-6 and similar levels of anti-inflammatory IL-10 when compared to the skin.

D. Grainger: What is known about how commensal flora avoid the plethora of antimicrobial agents produced mutually in this context?

Authors: The huge number of strains present means that specifics of interspecies interactions have yet to be fully described. However, in other situations, such as the gut, commensal microorganisms decrease the production of toxins by other species of bacteria using quorum quenching. Additionally, competitive exclusion prevents anyone species from becoming dominant which subsequently keeps the concentration of individual bacterial toxins down. Meanwhile, commensals produce fewer toxins and as described in the manuscript commensal bacteria interact with the host immune system through chemicals such as enolase to prevent excessive immune activation. However, the variety of bacterial strains and species as existing in the oral cavity is considered a characteristic of the oral microbiome at health, providing stable protection against the plethora of antimicrobials mutually produced (Yang et al., 2011; Zarco et al., 2012).

R.G. Richards: The authors mention that joint arthroplasties are placed in largely "sterile" tissue. In my view, this statement does not really account for the flora of the skin, especially at the hair root follicles, which can be introduced into a wound upon opening with a scalpel. Patient history of whether they have had an infection at any time prior to operation is also not considered, as the bacteria can reside in stasis within cells - within the bone architecture (such as bone canaliculi, of the lacunae of ossified bone) itself - and are only active under opportunistic conditions, such as the implantation of an artificial joint. How do the authors consider these unregistered, unexplored avenues to the infections of joints? Or, do the authors believe that the infection is purely nosocomial in these cases?

Authors: It is true that the skin is far from a sterile environment; however, the number of bacteria typically contaminating an arthroplasty surgical site is still much reduced in comparison to those present in the oral cavity. This is especially true, due to the post-surgical closing of the wound associated with an arthroplasty, in comparison to the "open" dental device. In the case of the external fixator, the amount of bacteria present is much increased due to the mentioned skin microflora and this contributes to the much higher infection rates observed, as described in our opinion and discussion paper. It is also true that pre-existing infections constitute an important factor in the development of a new infection. However, this is a factor at all the implant sites discussed and therefore cannot be identified as specifically affecting one more than the other. The presence of bacteria in the tissue or arriving from other sources, haematogenously for example, may contribute to infection rates. However, the largest doses leading to infection are likely from external sources: the skin, operating theatre air or the oral cavity.

G.Rh. Owen: In this paper you quote the infection rate of dental implants as being 1.7-9.6\% over the implant lifetime, (over 10 years) compared to $4.0-96 \%$ in external fixator/transcutaneous pins (less than 100 weeks). Recent data suggests that dental implant infections are much higher than expected after 5 years. One publication suggests peri-implant mucositis (defined as a reversible inflammatory reaction in the soft peri-implant mucosal tissue) occurs in approximately $80 \%$ of subjects, affecting $50 \%$ of the implant sites, whereas peri-implantitis (defined as an inflammatory reaction associated with the loss of supporting bone) has been identified in $28-56 \%$ of subjects and $12-43 \%$ of implant sites, respectively. On what level of infection did you base your low infection rate?

Authors: In our manuscript, we try to make a clear distinction between infection and infection-associated failure. Infection does not necessarily lead to failure, which is why general infection rates are generally higher than the infection-associated failure rates reported in our manuscript.

R.G. Richards: The authors suggest a similarity between dental implants and transcutaneous pins. I would challenge this general assumption. Often external fixator pins are used for treatment of open wounds with large degrees of soft tissue damage, including vascular compromise and multifragmented bone pieces leading to instability. Each of these individual areas are known to increase the susceptibility to infection and the combination of each gives a totally different risk, compared to the dental situation. In my view, this is much more serious assault on the body compared to a dental implant, naturally giving rise to higher rates of infection. Please comment. 
Authors: The presence of trauma will be a factor in the development of host-responses. However, in all cases discussed the placement of the implants alone constitutes a major challenge for the host; for example, the drilling required to place a dental implant or the insertion of the hip arthroplasty stem into the femur. It is of course difficult to directly compare the three different surgeries in clinical settings given the diversity of the problems leading to the requirement for these implants. However, the rate of pintract infection is also high in limb-lengthening procedures, where the wound is controlled in comparison to an open wound from an incident of trauma (e.g. Antoci et al., 2008). This evidence further adds to the paradox.

G.Rh. Owen: Teeth are transmucosal organs, permanently exposed to the external environment, and underlying periodontal tissues are sealed by a soft-hard tissue interface known as the junctional epithelium. The goal of dental implant placement is to limit trauma to the soft tissue so that this seal can be regenerated. When making an incision in the skin for transcutaneous pins the skin barrier is compromised with minimal surgical strategies to seal the opening around the implant. In your view, what is the role of surgical technique and the importance of the seal between soft tissue and dental implants in reducing the level of infection?

Authors: The soft tissue seal represents a very important barrier to infection and indeed the importance of this seal is known in dentistry. The rapid formation of a soft tissue seal acts as a barrier to prevent pathogens from accessing the deeper tissue. This feature is further enhanced by the rapid healing associated with oral tissue discussed in this paper. In the case of external fixators, however, the transient nature of the implants means that extensive soft tissue integration reduces the ease by which the implant can be removed after use. This may also contribute to infection risk. In practice, the risk of infection at these weak points is countered by the strict hygiene regimes applied to these specific areas post-surgically. This gives an advantage over dental implants, where the soft tissue implant interface is often difficult to access and clean directly.

G.Rh. Owen: The junctional epithelium in teeth is a specialised structure, with functional adaptation to control the constant microbiological challenge experienced in the oral cavity. In your opinion, to what extent does the presence of the junctional epithelium influence the lower infection rates seen in dental implants?

Authors: The junctional epithelium represents a unique type of tissue at the implant interface, which possesses interesting immunological characteristics. This tissue acts as one of the first lines of defence in healthy oral tissue and also develops associated with implants. Many pathogens seek to compromise this tissue as it represents the route by which infection can develop associated with both teeth and implants. This specific tissue is an extension of the general unique immunology of oral tissue further adds to the hypothesis discussed in this paper: that oral immunology reduces infection risk.
G.Rh. Owen: The range of infection rates for external fixators/transcutaneous pins is variable (4-96\%) and can be influenced by many factors. Higher rates of infection in external fixator/transcutaneous pins have been seen especially in areas where there is dynamic movement of the implant. In the case of transcutaneous pins, this motion could be amplified due to implant length causing skin movement and irritation at the skin wound site. Have you considered the possibility of dynamic movement of an implant playing a part in the higher infection rates seen in external fixator/transcutaneous pins?

Authors: Movement in transcutaneous pins may contribute to increased infection risk by loosening the tissue around the implant and mechanically moving pathogens down the tissue. However, dental implants also experience a range of movement and in addition the pathogens are present suspended in liquid which would require less mechanical stimulation to enter the implant interface. Therefore, we consider this factor to be minor in the paradox.

R.G. Richards: In the early 90s, at the AO Research Institute Davos, Dr Henk Eijer (clinician) and Dr Slobodan Tepic (scientist) made a very interesting observation during infection studies comparing, 1) titanium and steel (Schlegel and Perren, 2006), and 2) compression plating versus locking plating for susceptibility to infection (Eijer et al., 2001; Arens et al., 2001). Various doses of S. aureus (clinical strain) were applied to rabbits between the plate and bone to determine the ID 50 for infection. Both studies were published, but in low doses of bacterial challenge (that did not cause clinical sign of infection) very high bone overgrowth was observed (unpublished). Recently I met Dr Slobodan Tepic and he strongly believes that exposure to the low bacterial challenge stimulated fast bone growth over the plates and that this could also stimulate faster bone healing through a modified immune response. As this is an opinion paper, and your thoughts indicate that continual bacterial exposure may reduce susceptibility to infection in the dental area, I would like your opinion on his idea that such exposure (like a vaccination) to a low bacterial challenge may speed up fracture healing through a modified immune response.

Authors: There is increasing evidence that the presence of low levels of bacterial contamination could increase healing (for example: Thomas and Puleo, 2011). The stimulation of the immune system by bacteria leads to the recruitment of immune cells, increased vascularisation and inflammation, all of which are involved in natural healing processes. However, excessive inflammation leads to the destruction of tissue as seen in inflammatory diseases. There could indeed be a balancing point at which healing is stimulated; however, very little is known about the development of immune responses in the presence of both biomaterials and bacteria. If it is possible to identify the pathways or specific signalling molecules which cause these phenomena it would be possible to deliver bacteria "inspired" treatments.

T.F. Moriarty: The authors propose one avenue of future therapy may be to provide "sterile tissues experience with 
bacterial pathogens through exposure to the most prominent pathogens threatening a particular type of implant". This is an interesting concept, although it could also in theory be a double edged sword as such "experience" may in fact potentiate infection. For instance, some polymicrobial infection models indicate that this may be the case. In any case, the most common bacterial species causing implant infection tend to include the staphylococci. These bacteria are common skin colonisers, and so each of us will already have "experience" of such species. How do the authors envisage exposing host organisms to such bacteria in a way that is not already covered by natural host : bacteria interactions.

Authors: Though it is true that that some bacteria potentiate infection, the application of specific bacterial components might be a method of exposing the host to pathogens without increasing infection risk. This may be particularly effective in the deeper tissues where unlike the skin there is typically no contact with bacteria. Furthermore, the application of components specific to bacteria may aid the immune response in targeting known pathogens.

R.G. Richards: In infection research healthy animals that have never had exposure to bacterial pathogens are generally used, which does not simulate the clinical situation. Do you feel that studies should be performed, testing the standard models against models where there has been exposure to low doses of bacterial pathogens.

Authors: Indeed, the lack of exposure of laboratory animals to pathogens is a limiting factor in infection research. This may be an interesting avenue of research to pursue, measuring the effect of exposure on immune responses in a standard model.

\section{Additional references}

Antoci V, Ono CM, Antoci V Jr, Raney EM (2008) Pin-tract infection during limb lengthening using external fixation. Am J Orthop 37: E150-E154.

Arens S, Eijer H, Schlegel U, Printzen G, Perren SM, Hansis M (1999) Influence of the design for fixation implants on local infection: experimental study of dynamic compression plates versus point contact fixators in rabbits. J Orthop Trauma 13: 470-476.

Charalampakis G, Leonhardt A, Rabe P, Dahlen G (2012) Clinical and microbiological characteristics of peri-implantitis cases: a retrospective multicentre study. Clin Oral Implants Res 23: 1045-1054.

Eijer H, Hauke C, Arens S, Printzen G, Schlegel U, Perren SM (2001) PC-Fix and local infection resistance - influence of implant design on postoperative infection development, clinical and experimental results. Injury. 32 Suppl 2: B38-43.

Schlegel U, Perren SM (2006) Surgical aspects of infection involving osteosynthesis implants: implant design and resistance to local infection.Injury. 37 Suppl 2: S67-73.

Thomas MV and Puleo DA (2011) Infection, inflammation, and bone regeneration: a paradoxical relationship. J Dent Res. 90: 1052-1061.

Yang F, Zeng X, Ning K, Liu KL, Lo CC, Wang W, Chen J, Wang D, Huang R, Chang X, Chain PS, Xie G, Lin J, Xu J (2011) Saliva microbiomes distinguish cariesactive from healthy human populations. ISME J 6: 1-10.

Zarco MF, Vess TJ, Ginsburg GS (2012) The oral microbiome in health and disease and the potential impact on personalized dental medicine. Oral Dis 18: 10 . 